\title{
STRETCH REFLEX IN AN EXTRA-OCULAR MUSCLE*† ELECTROMYOGRAPHIC FINDINGS IN A CASE OF ORBITAL FRACTURE
}

\author{
BY
}

\author{
I. NAWRATZKI ${ }^{1}$, H. ZAUBERMAN ${ }^{1}$, A. MAGORA ${ }^{2}$, AND J. CHACO ${ }^{2}$ \\ From the Department of Ophthalmology ${ }^{1}$, and the Department of Physical Medicine and Rehabilitation ${ }^{2}$, \\ Hadassah University Hospital, Jerusalem, Israel
}

DistuRBANCE of eye motility associated with orbital fractures is a frequent finding. Because it is not always easy to determine the nature of the muscle disorder clinically, electromyographic (EMG) investigations have been undertaken in a few cases. Normal responses were found in two cases after orbital fracture by Björk (1954), and neurogenic patterns were found in three cases by Maggi and Millefiorini (1963). In one case, following a skull fracture, simultaneous discharges were found in several muscles, proving an aberrant regeneration of nerve fibres as the underlying cause (Breinin, 1957a).

The purpose of this report is to describe a case in which a "pseudo-paradoxical" EMG response of the involved inferior rectus muscle was found.

\section{Case Report}

A man aged 21 was referred to the strabismus clinic because of diplopia which appeared immediately after a scooter accident, 5 months previously. X-ray examination showed a nasomaxillar fracture with downward displacement of the floor of the right orbit.

Examination.-The visual acuity was $6 / 6$ in both eyes and the media and fundi were normal. The right eye presented slight enophthalmos. A typical "dish face" was noted.

There was a slight head-turn to the right, with chin depression. Eye movements showed a marked limitation of the right inferior rectus muscle (Fig. 1). Diplopia was present in all directions of gaze, and was especially troublesome on looking down and down to the right.
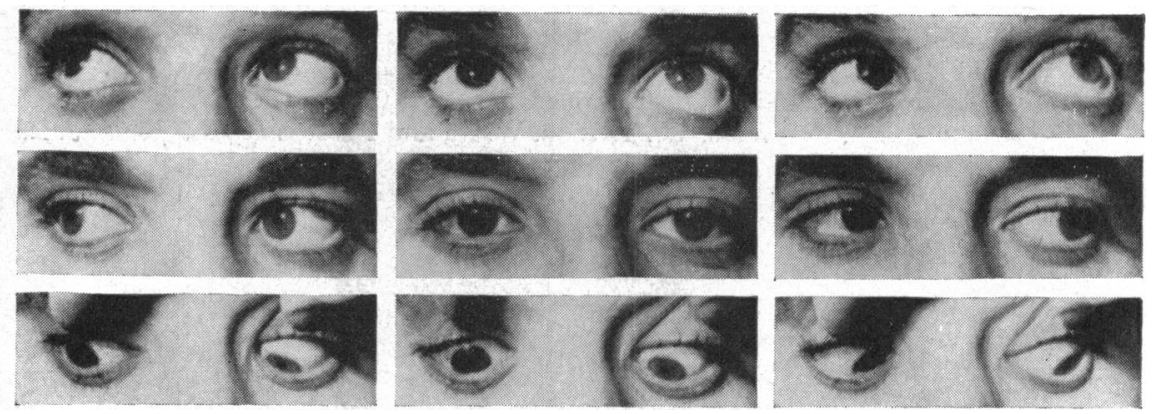

FIG. 1.-Limitation of right eye on looking down and down to the right.

The Hess chart showed a marked limitation of the right eye depressors and an overaction of the left superior oblique muscle (Fig. 2, opposite).

The traction test showed that the passive movements of the right eye were free in all directions.

* Received for publication May 22, 1967.

† Address for reprints: 

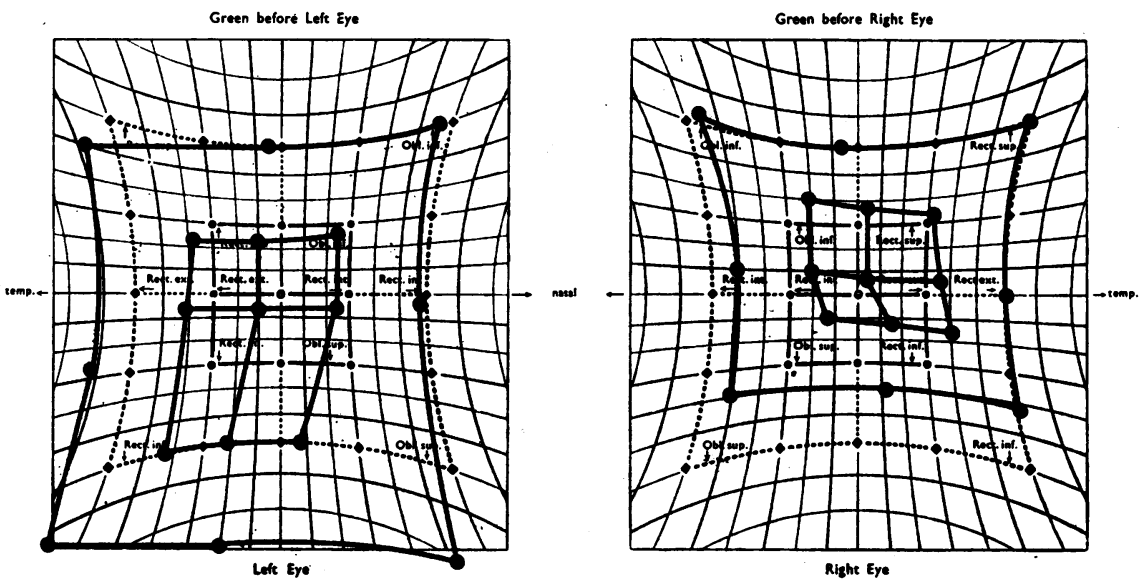

FIG. 2.-Hess chart shows marked limitation of right eye depressors and overaction of left eye depressors.

Electromyography.-The EMG examination of the right inferior rectus muscle gave the following results:

On looking down and down to the right (the primary kinesiologic field of the inferior rectus), there were action potentials of normal amplitude $(300-500 \mu \mathrm{V})$ and normal duration $(0.9-1 \cdot 2 \mathrm{msec}$.) (Fig. 3). The interference pattern was full.

FIG. 3.-Electromyographic recording of right inferior rectus muscle on looking down and down to the right.

Calibration $300 \mathrm{~V}$.

Time base $1 \mathrm{msec}$.

The recording shows a full, high frequency interference pattern with normal parameters. Amplitude 300-500 V. Duration 0.9 $1 \cdot 2$ msec.

The average of amplitude and duration was determined by computer analysis.

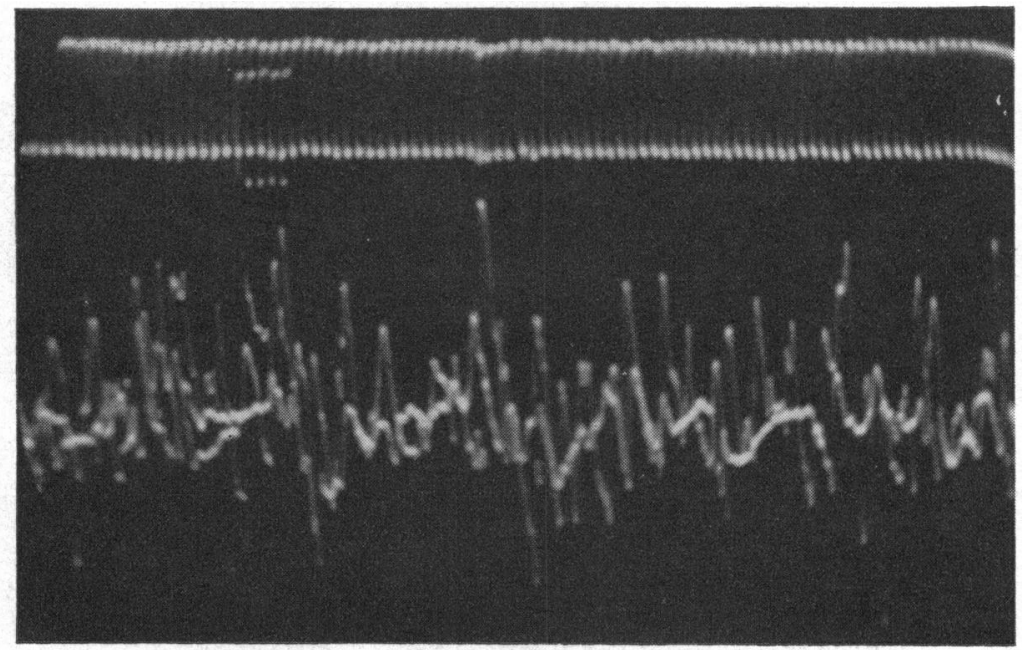

On looking straight up and up to the right (the primary field of action of the superior rectus), the inferior rectus continued to show EMG activity, though of a lesser amplitude (100-200 $\mu \mathrm{V})$ (Fig. 4, overleaf).

Movements in all other directions showed no EMG activity in the inferior rectus.

Operation.-A 4-mm. resection of the right inferior rectus was performed to try and reposition the globe in the physiological primary position and thus to eliminate diplopia.

Result.-Within 2 months of the operation, a gradual clinical improvement occurred, leading to an almost complete disappearance of diplopia (Figs 5 and 6, overleaf).

An EMG examination of the right inferior rectus showed normal electrical activity of the muscle in its primary field of action, but activity previously shown on looking up and up to the right was no longer observed. 


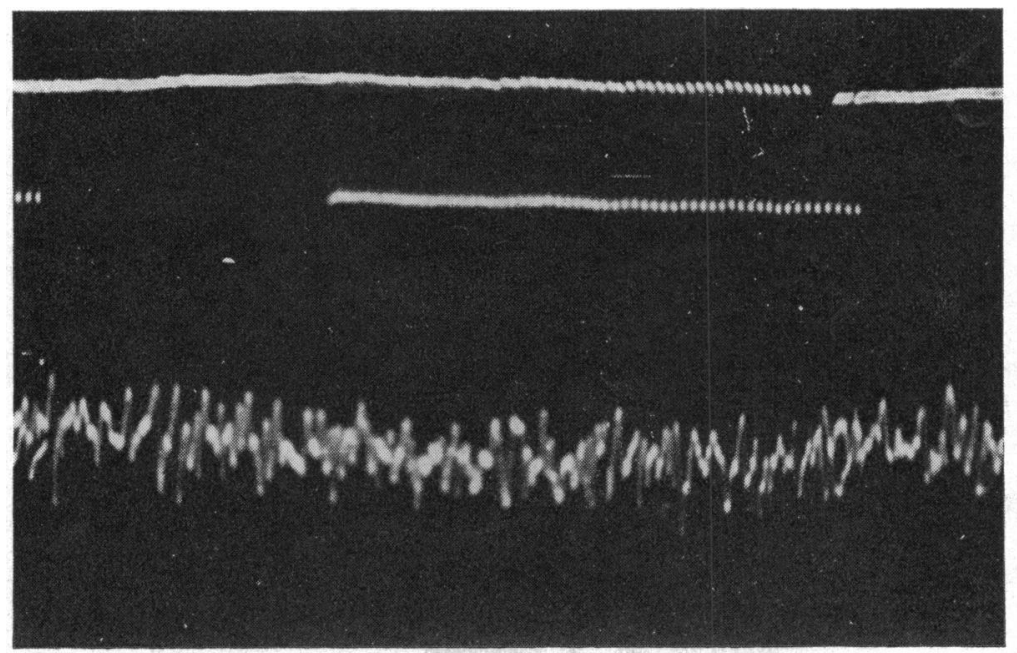

FIG. 4. - Electromyographic recording of right inferior rectus muscle on looking up and up to the right.

Calibration $300 \mathrm{~V}$

Time base $1 \mathrm{msec}$.

The EMG recording shows normal duration $(0.8-1 \cdot 2$ msec.) and a full interference pattern, but the amplitude is markedly lower $(100-200 \mathrm{~V})$ on repeated relocations of the needle electrode.

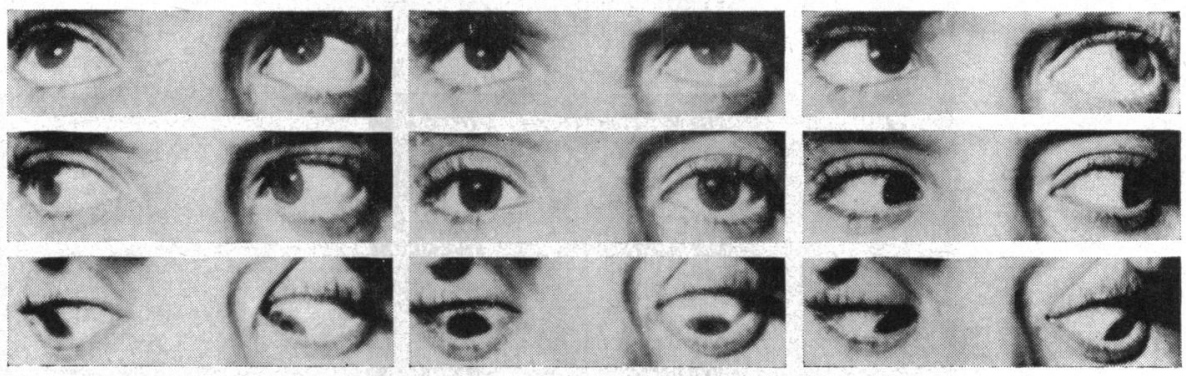

Fig. 5.-Motility of right eye greatly improved on looking down and down to the right.
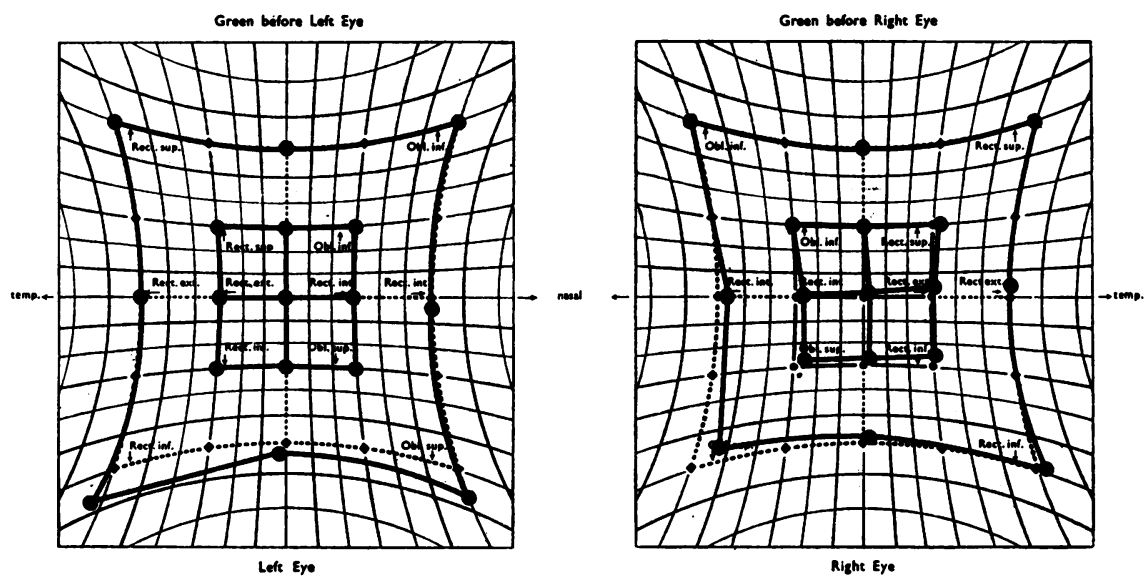

Fig. 6.-Hess chart corroborating clinical improvement of right eye as shown in Fig. 5. 


\section{Discussion}

This case is of interest because the affected muscle has shown electrical activity in the field of action of its antagonist. The immediate disappearance of this unusual electrical activity after corrective surgery excludes a paradoxical innervation, which could have been caused by an aberrant regeneration of nerve fibres. Furthermore, the possibility of secondary contraction of the inferior rectus muscle is excluded by the negative traction test and the confinement of EMG activity to special directions of gaze (downwards, and upwards to the right).

It would appear that a more likely explanation is the mechanical disadvantage and consequent overstretching of the inferior rectus which followed the displacement of the globe backwards and downwards. This overstretching of the inferior rectus takes place in the field of action of the superior rectus, its direct antagonist, but does not occur in other directions. Figs $7 a, b$ contrast the normal situation with the abnormal circumstances of this case.

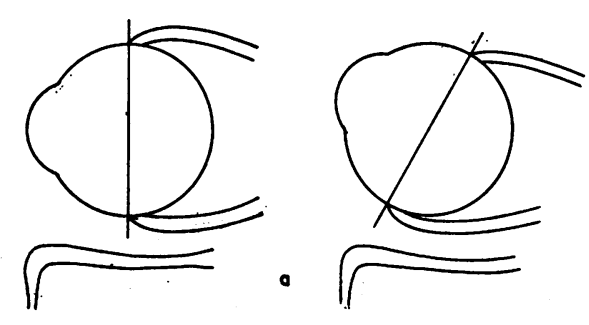

FIG. 7a.-Normal interplay of inferior rectus and superior rectus muscles in forward and upward gaze.

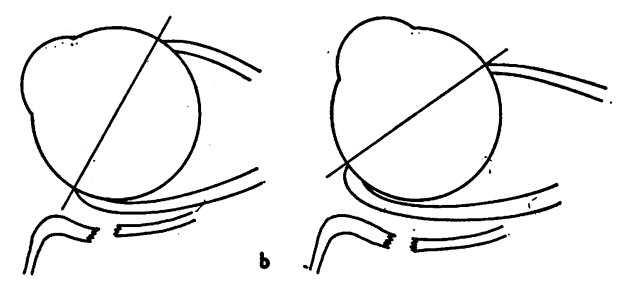

Fig. 7b.-Stretched inferior rectus muscle on displacement of the globe backwards and downwards, and "over-stretching" on upward and lateral gaze.

It is known that, when a muscle is stretched beyond a certain point, a myostatic reflex is brought into play which causes active contraction (Breinin, 1957b; Davson, 1963). The presence of unusual nerve endings, muscle spindles, and other low threshold receptors may act as the sensory element in this "stretch reflex" (Cooper, Daniel, and Whitteridge, 1955).

\section{Summary}

(1) A case is described of fracture of the orbital floor with displacement of the globe backwards and downwards, impaired motility of the inferior rectus muscle, and resulting diplopia.

(2) The electromyographic reaction of the affected inferior rectus demonstrated electrical activity not only in the field of action of the muscle, but also on movement upwards and upwards to the right. This electromyographic reaction disappeared immediately after successful resection of the affected inferior rectus muscle.

(3) It is concluded that the pre-operative abnormal electromyographic response was not due to an aberrant regeneration of nerve fibres nor to a contracture of the inferior rectus muscle. Evidence is brought forward that a "stretch mechanism" was responsible for the pseudo-paradoxical electromyographic response of the inferior rectus. 


\section{REFERENCES}

BJöRK, Å. (1954). Brit. J. Ophthal., 38, 528.

Breinin, G. M. (1957a). AMA Arch. Ophthal., 58, 375.

(1957b). Ibid., 57, 176.

Cooper, S., DANiel, P. M., and Whitteridge, D. (1955). Brain, 78, 564.

Davson, H. (1963). "The Physiology of the Eye", 2nd ed., pp. 235-236. London.

MAGGI, C., and MillefioRINI, M. (1963). Riv. oto-neuro-oftal., 38, 577. 